\title{
Alberta's Digital Oilfield: Technological Opportunities and Benefits for Alberta Companies and Communities
}

\author{
Stephen Rausch, BMgt, Ec.D. (2019 candidate) \\ The global oil and gas sector has recently undergone a significant shift in supply \\ economics, which has rippled throughout the supply chain. This has been felt as strongly \\ in Alberta, Canada as it has in any other oil producing region. The intense need for \\ operational changes to production, coupled with the proliferation of digital technologies \\ into industrial processes (Industry 4.0), has led to new opportunities to dramatically \\ reduce costs and inefficiencies through the supply chain. These opportunities can be \\ summarized as Digital Oilfield Technologies, which are a combination of tools and \\ disciplines that are incorporated into advanced software to improve operations \\ efficiencies. This paper explores the different types of Digital Oilfield Technologies, its \\ benefits to industry, and uncovers how communities in oil and gas producing regions can \\ support the growth of this new subsector to improve the health of local industry and \\ economy.
}

Keywords: oilfield technology, oil and gas, oilfield optimization, digital analytics, digitalization, industry 4.0

\section{Introduction}

The modern oil and gas industry has been essential to the world economy since the early $20^{\text {th }}$ century, with drilling and refining dating back well before 1880. Since then, industry advancements have been characterized by technological achievements that improved efficiency, opened access to new reserves, enabled broad distribution, and unlocked new end products. The first commercial oil well in both Canada and North America became operational in 1858, with the majority of extracted crude oil being refined into lamp oil kerosene at the time (Habashi, 2000). Leduc No. 1 was the first major crude oil discovery in Alberta and resulted in a boom of exploration and development that continues to drive the province's economy to this day. Since early days, the industry has continued to witness numerous improvements by way of new drilling capabilities, greater refining capacity, and an expanded value chain.

There is no shortage of current challenges facing the oil and gas industry, particularly in Alberta. These issues include rising labour costs, growing capex (capital expenditure) requirements for development, tighter regulations, regional oil price discounts, restricted access to world markets, and natural disasters; all of which, are becoming more common. The industry continues to be shaped in significant ways by new technology that aims to mitigate these risks, and address an increasingly competitive market, which resulted in bottom line improvement of corporate balance sheets. Since the year 2000, numerous tech products and services have matured from early-stage concepts to offerings capable of transforming entire industries. We are now seeing these effects impact oil and gas operations in real time, and they can collectively be referred to as "Digital Oilfield Technologies". 
Digital Oilfield Technologies encompass a wide variety of tools, tasks, and disciplines that are incorporated in advanced software and data analysis techniques to deploy integrated workflows that improve efficiencies (PetroWiki, 2017). By combining workflows with advanced IT and engineering expertise, most business processes can become automated and improve return on capex. This underlying premise is driving an increase in the adoption of Digital Oilfield Technologies across the entire value chain that is improving return on investments by reducing operating costs, increasing output, and eliminating unscheduled shutdowns (Mittal, 2017). Digital Oilfield Technologies is an industry specific term that refers to the fourth industrial revolution, which describes the exponential changes to the way we live, work and relate to one another due to the adoption of cyber-physical systems, the Internet of Things and the Internet of Systems (Marr, 2018). In a 2016 industry report by June Warren-Nickle's Energy Group (JWN Energy Group), Jeff Freeman, Chief Technology Officer at Zedi, was cited as stating that a top down approach is needed to implement these new technologies,

"The true realization of the Digital Oilfield vision comes not in the field, but in head office, and how producers change their business processes to leverage analytics and to integrate the silos that can exist, for example, between the exploration and production sides of the business. Unlocking this potential is as much about people and process as it is about technology." (JWN Energy Group, 2016)

Digital Oilfield Technologies can deliver a distinct blend of benefits for each oil and gas company, depending on its own unique corporate structure, activities, and position in the supply chain. It would be within reason, however, to suggest that there are broad common benefits experienced by organizations that successfully incorporate Digital Oilfield Technologies into their workflows, including: faster and better decision making, faster production, reduced risk, cost reductions, and operational efficiencies. These industry benefits could possibly provide net positive secondary effects on the communities in which they are adopted. As new technologies are embraced by industry, there is the potential for business investment from new sectors, a wider variety of job opportunities, innovative post-secondary research streams, and the chance to compliment an existing cluster.

This paper aims to uncover how communities in Alberta can facilitate the growth and expansion of Digital Oilfield Technology companies to improve operations of our bellwether oil and gas sector. To provide valuable recommendations, an accurate assessment will first be made by reviewing the technology types, supply chain impacts, benefits, challenges, and Alberta's regional environment.

\section{Types of technology}

Although there is an endless breadth of unique Digital Oilfield Technologies, it is helpful to categorize them by functionality. The following list summarizes technologies with examples of what industry discipline it affects. Note that in many real-world cases, there is a high degree of overlap in the usage and benefits of various technology types. 


\section{Predictive maintenance}

Data is created from actual usage patterns of equipment and then analyzed to determine when servicing is really required, as opposed to relying on a pre-set recommended maintenance schedule. This reduces the chance of unexpected asset failure, and the subsequent repair costs.

Examples:

- Fleet management

- Historical usage records

- Predictive algorithms

- Digital notifications (such as e-mails) from equipment

\section{Production and asset optimization}

Optimization improves the capabilities of existing equipment and assets, adding more value to either the end product or the asset itself.

Examples:

- In-field and precision manufacturing (3D printing)

- Virtual twin facilities (an exact digital copy of a physical facility used to test scenario models)

- Fuel efficiency software (i.e. optimized route selection)

- Smart pumps (enabled by the Internet of Things)

- Plug and play projects (equipment designed for efficient use and simple reuse)

\section{Operational efficiency and safety}

Equipment and software can increase the ratio of outputs to inputs, or reduce risks to labour.

Examples:

- Smart zones/asset tracking (geo-fences around an area that reduce the possibility of incidents)

- Unmanned autonomous vehicles (drones, trucks, etc.)

- Remote monitoring of equipment that does not require a human onsite

- High-risk wearables (detects dangerous environments or biometric warning signs)

\section{Collaboration}

The means of increasing communication and collaboration can be characterized through advancements that promote the sharing of a greater amount of information that is also more accurate, and available in less time.

Examples:

- Blockchain trading (secure peer-to-peer exchange record that reduces transaction costs) 
- $5 \mathrm{G}$ wireless technology (the next era of wireless technology, deployment beginning in 2018)

- Intelligent wearables (hands-free equipment with HUD displays, live data, and communications support)

\section{Decision support}

There are a number of tools that help improve the decision-making capabilities of leadership, and it can be argued that all Digital Oilfield Technologies accomplish this indirectly. However, this is the primary purpose and benefit of a narrow subset of tools.

Examples:

- Big data (the collection of extremely large data sets that require vast computing resources)

- Cognitive computing (AI) and data analytics

- Mobile devices (field tablets)

- Smart data forms

\section{Data integration and workflow automation}

The Internet of Things (IoT) summarizes the interconnection of computing devices embedded in machinery and equipment, via the cloud, to enable the sending and receiving of data. This is demonstrated in control centres that have the capability to collect information in real-time from a multitude of sources, synthesize the data to make operational decisions, and broadcast out commands.

Examples:

- Internet of Things (IoT)

- Cloud computing

\section{Supply Chain Streams and Digital Oilfield Impacts}

Three major supply chain streams make up the oil and gas industry: upstream, midstream, and downstream. Each stream is a subsection of the industry's supply chain, and provides unique opportunities to leverage Digital Oilfield Technologies in operations and management. It is important to note that many oil and gas companies are vertically integrated across multiple streams, which encourages the adoption of Digital Oilfield Technologies that have an impact on multiple links in the supply chain. Figure 1 (following page) outlines how advancements are improving the efficiency of oil and gas companies in all three streams.

\section{Definitions:}

Upstream - comprises exploration and production. These operations include the search for potential underground crude oil and natural gas fields, drilling exploratory wells, and operating the wells that recover and bring the oil and gas to the surface. 
Midstream - defined as the transportation (by pipeline, rail, barge, oil tanker or truck), storage, and wholesale marketing of oil and gas products. Midstream operations often include elements of the upstream and downstream sectors, such as natural gas processing plants that purify raw natural gas.

Downstream - the refining of crude oil and further processing of natural gas, followed by the marketing and distribution of end products derived from petrochemical plants. Examples of end products include diesel, gasoline, asphalt, fertilizers, and hundreds of petrochemical products. *see Benefits of Digital Oilfield Technologies section for potential benefits of technology on each of the supply chain streams 


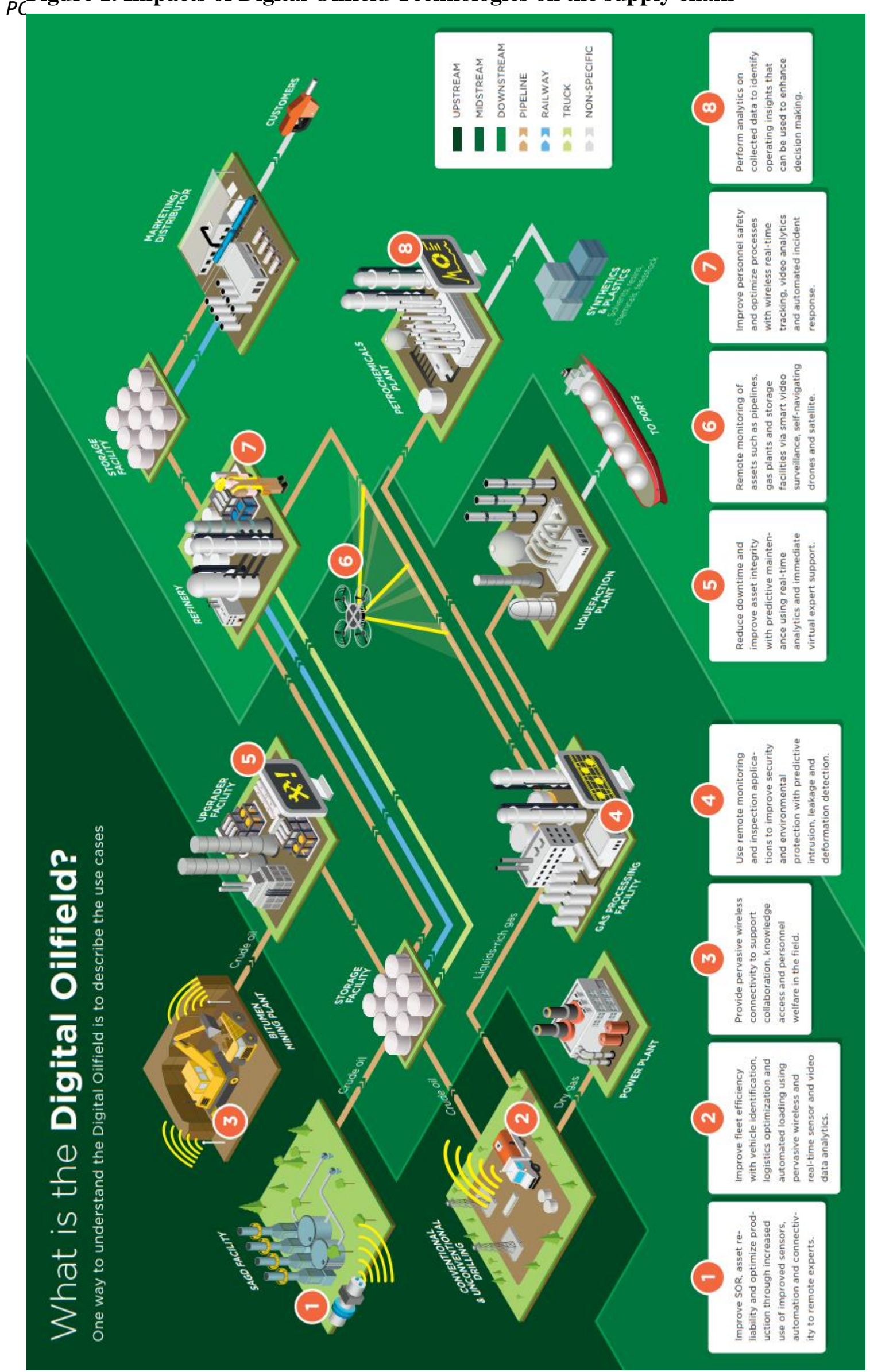




\section{Benefits of Digital Oilfield Technologies}

Digital Oilfield Technologies carry both positive and negative effects, as is seen with all technological advancements. This section will focus on the value realized when the various types are adopted and implemented into large scale oil and gas operations. According to the recent IHS report, commissioned by Canadian Energy Research Institute's (CERI) IHS report, 'oilfield digitization improves productivity by $2 \%$ to $8 \%$, with an operating expense reduction of $5 \%$ to $25 \%$ and a capital expenditure reduction from $1 \%$ to $10 \%$ depending on site localization' (Smith, 2017). This benefit of Digital Oilfield Technology can largely be summarized as an overall increase in net revenue. Most industry professionals who have been surveyed predict that added value represented by new Digital Oilfield Technologies to be in the range of $\$ 50$ milltion to $\$ ! 00$ million (JWN Staff, 2017). They also perceive most operations will become fully automated in 3-5 years. For the purposes of this paper, benefits below are specifically attributed to their most directly impacted functions:

Better Data (faster and better decision making)

- Sensors

- Big data and cloud computing

- 5G wireless

Increased production

- Virtual twin facilities

- AI and data analytics

- Smart pumps

Reduced risk

- Smart zones and asset tracking

- UAVs (unmanned autonomous vehicles)

- Remote monitoring and high-risk wearables

Supply chain pricing compression

- Blockchain trading

Operational efficiencies

- Fleet management

- In-field and precision manufacturing

- Field tablets, intelligent wearables and mobile devices

Reductions to capex (capital expenses) and opex (operating expenses)

- Fuel efficiency software

- Predictive maintenance 
- Plug and play projects

Impacts on the supply chain

Each stream, itemized below, will realize the greatest benefits from specific types of technology, and widest adoption.

Upstream: smart pumps, AI and data analytics, virtual twin facilities, smart zones

Midstream: storage system analysis, sensors, remote monitoring

Downstream: UAVs, fleet management, precision manufacturing, blockchain trading

Real-world examples of Digital Oilfield Technology benefits:

GE uses proprietary software to create a digital twin of a steam-assisted gravity drainage (SAGD) project to optimize operations. GE said it produced a $1 \%$ to $1.5 \%$ improvement in steady state operations and a $3 \%$ to $5 \%$ improvement in non-steady state production across a SAGD producing field. Even a $1 \%$ improvement in production can yield millions of dollars in additional revenue annually (Smith, 2017).

SAS, a global leader in the digital analytics industry, has developed an asset optimization system for thermal oilsands producers that creates models able to compute optimal steam distribution on a field-wide basis. SAS estimates its technology can produce an additional $40 \mathrm{bbls} / \mathrm{d}$ per well, which on a 100-well-pair facility would translate into a production increase of about 1.4 million barrels annually or $\$ 24$ million in increased pre-royalty cash flow with oil priced at $\$ 46 / \mathrm{bbl}$ (Smith, 2017).

Calgary-based Stream Systems has developed a cloud-based software-as-a-service application that allows users to customize and test their projects in a virtual environment to extract maximum value from large capital investments. It can trim $20 \%$ off the costs of capital projects by testing in a risk-free, virtual environment (Smith, 2017).

Suncor Energy, which has a fleet of about 100 heavy haulers, is piloting the (driverless vehicle) technology with 400-tonne Komatsu Front Runner autonomous haul trucks as part of a larger shift toward increased automation in mining. Able to be remotely controlled and operated 24/7, GPS-assisted autonomous heavy haulers, which have also been developed by Caterpillar, are expected to cut costs five to 10 per cent (Smith, 2017).

OPEX Corporation is a workflow automation company that serves clients, including oil and gas companies, by improving administrative processes. OPEX vice-president of Operations, Chris Ayres, stated:

"Oil and gas operators have a significant opportunity to secure additional production revenue by unlocking the immense value in their operational data. Each of our customers is different, but our experience has shown a typical $2 \%$ to $5 \%$ improvement in production and a $50 \%$ reduction in critical system outages." (JWN staff, 2018) 


\section{Implementation challenges}

The proliferation of new technology available to the oil and gas industry, brought on by the fourth industrial revolution, is "creating all this uncertainty in a lot of different industries as to whether they have to get on the bandwagon or not: Is it going to impact them today? Or can they retire first and hopefully it impacts the next generation?" according to GE Canada President Elyse Allan (Roche, 2017).

The most significant barriers to faster implementation of digital oilfield technology have one thing in common: they are all internal business-related hurdles. These are the most common technology adoption barriers:

- Insufficient knowledge (example: unclear ROI)

- Fear of cyber-attacks (security)

- Risk adverse culture of oil and gas industry

- Employees (example: resistance to change, lack of qualified employees)

- Budget constraints

Both vendors and users of Digital Oilfield Technologies need to become more proactive making the business case to overcome technology implementation resistance. This starts with greater overall understanding of technology offered and the benefits within an organization. In JWN's 2016 Digital Oilfield Outlook Report, respondents to a survey indicated for the second year in a row that the two biggest perceived barriers to implementation are: budget constraints and the existence of organizational barriers (JWN, 2016). Thus, it is not the technology itself that is the biggest adoption hurdle, but a lack of technology knowledge and awareness within oil and gas businesses. Further, not having a clear understanding of the benefits suggests the need for a bottom-line business case to help move implementation forward.

There are four key themes to addressing the current barriers restricting greater adoption of Digital Oilfield Technologies:

- Deepen awareness

- Encourage collaboration

- Identify champions

- Expand the conversation 


\section{Alberta regional profile}

The broad definition of Digital Oilfield Technologies allows for crafting unique solutions to niche problems throughout the industry vertically and across geographic areas. The opportunities to develop and test these technologies in the harshest of environments could create a bridge between tech clusters and the oil and gas world. The Edmonton area (including Strathcona County) is uniquely positioned to become a key Digital Oilfield Technology hub (McSweeney \& Associates, 2015).

Globally, Alberta's oil and gas cluster is unique: its harsh and seasonal climate causes significant swings in production, many projects are in remote locations, and extraction methodology varies throughout the province. Furthermore, the province's industry cluster is very much vertically and horizontally integrated which assists companies to develop and integrate Digital Oilfield Technologies that are unique to their position in the supply chain.

Distinctive factors such as these create a favorable test setting for firms based in Alberta, or those using digital oilfield equipment in the province. Rough isolated terrain, extremely cold winters, and constant changes in environmental dynamics are the components of a real-life laboratory that can push the performance of new equipment to its limits and beyond. Strathcona County is ideally located for testing due to the nearby assets such as: University of Alberta, Northern Alberta Institute of Technology's (NAIT) Centre for Sensors and System Integration, a healthy local startup ecosystem, and significant industry pressure. For example, companies working with NAIT on the development of new sensor technologies are supported by government incentives and retain the intellectual property rights.

Another competitive strength is the need for data collection and use by digital oilfield equipment that can be processed and analyzed as close to the source as possible (McSweeney \& Associates, 2015). Due to the sheer scale of data that is being collected, it is preferable to not transmit data using cloud technologies, but instead to process it onsite. Onsite data processing is also known as, 'Edge Computing' and is required for many technologies used by digital oilfield equipment such as: wireless sensor networks, mobile signature analysis, distributed data storage, and augmented reality. Proximity to operational facilities makes regions like Strathcona County an ideal location for collecting and processing big data generated by oil and gas companies.

\section{Examples of Alberta-based companies that are developing Digital Oilfield Technologies:}

Hifi Engineering Inc applies fibre-optic monitoring technology to wells and pipelines to reduce leaks and spills by preventing problems such as corrosion. Hifi does this by monitoring three key data points, acoustic energy, strain, temperature, enabling operators to know where issues are occurring. Hifi's own algorithm is coupled with GE's Predix operating system (Haydu, 2017).

Blackline Safety created the world's first fully connected, work-anywhere safety device with expandable gas detection capability. It combines $3 \mathrm{G}$ wireless, two-way speakerphone and live 
monitoring capabilities. In effect, the G7 combines a gas detector, a lone-worker safety device and a communications tool into one high-tech wearable device (Smith, 2017).

Ambyint uses iPhone-sized computers, digital signals and complex algorithms to control the flow of oil from older wells, boosting output and avoiding downtime (Wethe, 2017).

Veerum is combining asset tracking, digital twin technology, and virtual reality with the use of robots, drones, lasers, and photogrammetry to improve project delivery (Jaremko, 2017).

\section{Future}

In 2017, Accenture Consulting and Microsoft conducted the $6^{\text {th }}$ edition of their Upstream Oil \& Gas Digital Trends Survey. Over 300 respondents working in the oil and gas industry from 18 different countries provided input on current and future trends. These respondents see big data and analytics, cloud, Internet of Things (IoT), mobility, high performance computing (HPC) and cybersecurity as having the greatest potential to transform their businesses. In the next three to five years, $70 \%$ plan to spend more or significantly more on digital technologies as well as the next wave includes HPC, wearables, robotics, artificial intelligence and blockchain. (Accenture, 2017)

Given these signs, digital oilfields will eventually become automated oilfields that require less day-to-day oversight transforming how oil and gas companies conduct business. Thus, the financial impact of individual decision can be tracked granularly increasing transparency to stakeholders. All information pertaining to the acquisition, development, production, and disposition of oil and gas assets (will be) managed in a centrally-administered system with BPM processes, orchestrated workflows, and notifications. (PetroWiki, 2017)

What does this changing future mean for companies looking to implement digital oilfield solutions, and communities that seek to empower their local industry and increase its competitiveness? Any suggested actions must stem from an accurate analysis of internal and external factors, and support four key themes: awareness, collaboration, champions, and conversation.

\section{Recommended Community Actions}

Review asset compilation and external environment to identify key community strengths and gaps

A full SWOT analysis of a community's internal and external factors is critical to understanding if the right ingredients are present to support adoption of Digital Oilfield Technologies. This is essential for determining primary targets to pursue, identifying stakeholders and champions, and assessing the competitive strengths of assets - all key components of an economic development strategy. 
Set specific \& realistic goals for business expansion/attraction related to Digital Oilfield Technologies

A community assessment will help determine the local opportunity for adoption of Digital Oilfield Technologies by existing industry and thus, the possibility of attracting firms specializing in this field. For example, a community lacking a large enough oil and gas industry presence to experience clustering effects may determine that the most appropriate goal is to facilitate local technology firms in developing offerings for out-of-market customers.

Develop the vision and create a roadmap to leverage and promote strengths, while addressing gaps

With realistic goals agreed upon, it becomes possible for a community to plan the growth path from its current state into a future vision that is supported by local assets and strengths. This plan is a strategic document focused specifically on encouraging growth within the digital oilfield technology subsector. Activities, timelines, and responsibilities should all be captured and referenced.

Encourage regular stakeholder collaboration to build a foundation for uncovering new opportunities

Possible community stakeholders extend beyond local leading-edge companies to also include research institutes, post-secondary education, industry associations, and more. Stakeholder groups not only offer invaluable insights towards opportunities, but can provide meaningful feedback on strategies and build awareness beyond typical community communication networks.

Facilitate regional and cross-industry communication with a focus on expanding the conversation

Reaching beyond direct stakeholders, regional and cross-industry communication aims to develop informal channels for discussion with groups that are not directly engaged in Digital Oilfield Technologies. This can include working with neighbouring communities, or industries outside of the oil and gas or technology sectors. Desired outcomes include novel ideas or product relationships, and can serve to cement the image of a community as a subject matter expert.

\section{Direct targeting of digital technology companies not located in Alberta}

A key component of an expansion/attraction strategy is formal communication with companies that are identified as best fits to invest in Digital Oilfield Technologies in a community. This will depend upon your unique value proposition, but could include global Big Data firms, small oilfield technology producers, AI start-ups, or local suppliers that utilize advanced manufacturing. The initial goal should be to start a dialogue and collect intel on external perceptions of the community's readiness for the sector, but a professional information package should also be prepared to advance the conversation. 
Identify champions to deepen awareness by promoting real-world results and community strengths

Industry leaders, local politicians, and subject matter experts are all examples of people who could become champions for promoting the growth of a new industry in a community, such as Digital Oilfield Technologies. Armed with relevant data, they will help to build awareness across a wide spectrum, and solicit broad buy-in through their public support.

Encourage innovation through use of incentives to capitalize on talent of existing or new businesses

Creating and implementing incentives programs can provide another avenue for communities to encourage innovation. These can be creatively developed to go beyond the form of financial grants through offerings such as: consulting services, hiring support, free use of public spaces, and much more. A dynamic industry like oil and gas can be fragile and any net impact from innovation, financial or otherwise, could be the difference between survival and success.

\section{Conclusion}

With major oil and gas companies planning greater adoption of new technologies in the nearterm and the potential for far-reaching effects that are industry-wide, it is essential that communities in Alberta align to ensure that investment sources see the province as an ideal location to expand the newest subsector of the oil and gas industry. Alberta's distinct challenges require solutions that are equally unique, providing a dynamic test environment for regional Digital Oilfield Technology providers. The above recommended community actions will assist to improve awareness and collaboration in Albertan communities. The actions serve as the foundation for a long-term strategy to support new subsectors such as Digital Oilfield Technologies. These steps could assist a community with creating a more resilient local industry and tax base. For oil and gas companies themselves, the decision to incorporate these technologies will come down to dollars and cents, which, may possibly be the strongest case to do so.

\section{Author biography}

Stephen Rausch works as a Senior Business Development Specialist in Economic Development for Strathcona County, leading the development of diversification activities in critical valueadded sectors. Stephen has over a decade of experience guiding major projects for multinational corporations, not-for-profit organizations, and governmental institutions. This includes the development of partnership portfolios and attraction of large-scale investment for the Edmonton Oilers, Edmonton International Airport, University of Alberta, and City of St. Albert. 


\section{References}

Accenture. (2017, October 25). Upstream Companies Expect Shorter Time to Produce Oil and Gas Due to Digital Technology Investments, Finds New Research from Accenture and Microsoft. Retrieved 06 29, 2018, from Accenture:

https://newsroom.accenture.com/news/upstream-companies-expect-shorter-time-to-produce-oiland-gas-due-to-digital-technology-investments-finds-new-research-from-accenture-andmicrosoft.htm

Habashi, F. (2000). The First Oil Well in the World. Bulletin for the History of Chemistry, 64.

Haydu, C. (2017, September 19). Hifi Engineering jumps into pipeline politics with new fibre optic sensing tech. Retrieved 01 22, 2018, from JWN Energy:

http://www.jwnenergy.com/article/2017/9/hifi-engineering-jumps-pipeline-politics-new-fibreoptic-sensing-tech/

Jaremko, D. (2017, 04 03). Calgary startup applying digital twin technology to reduce oil and gas capital costs. Retrieved 01 22, 2018, from JWN Energy:

http://www.jwnenergy.com/article/2017/4/calgary-startup-applying-digital-twin-technologyreduce-oil-and-gas-capital-costs/

JWN. (2016). Digital Oilfield Outlook Report. JWN.

JWN Staff. (2017, 10 25). Digital technology can shorten time to produce oil and gas. Retrieved from JWN Energy: https://www.jwnenergy.com/article/2017/10/digital-technology-can-shortentime-produce-oil-and-gas-survey/

JWN Staff. (2018, January 10). Big data revolution boosts offshore production. Retrieved February 11, 2018, from JWN Energy: http://www.jwnenergy.com/article/2018/1/big-datarevolution-boosts-offshore-production-oil-gas-uk/

Marr, B. (2018, August 13). The $4^{\text {th }}$ Industrial Revolution Is Here - Are You Ready? Retrieved from Forbes: https://www.forbes.com/sites/bernardmarr/2018/08/13/the-4th-industrialrevolution-is-here-are-you-ready

McSweeney \& Associates. (2015). Strathcona County Foreign Direct Investment Strategy \& Implementation Plan. Strathcona County: McSweeney \& Associates.

Mittal, V. (2017). The Next-Generation Digital Oilfield. Oil \& Gas Financial Journal.

PetroWiki. (2017, February 18). Digital oilfields. Retrieved from PetroWiki: http://petrowiki.org/Digital_oilfields

Roche, P. (2017, March 3). Canadian oil and gas isn't moving fast enough to seize the digital oilfield opportunity. Retrieved February 11, 2018, from JWN Energy: 
http://www.jwnenergy.com/article/2017/3/canadian-oil-and-gas-isnt-moving-fast-enough-seizedigital-oilfield-opportunity-ge-canada-president/

Smith, M. (2017, July 24). Alberta company brings oil and gas lone worker tech to the digital age. Retrieved 01 22, 2018, from JWN Energy:

http://www.jwnenergy.com/article/2017/7/alberta-company-brings-oil-and-gas-lone-workertech-digital-age/

Smith, M. (2017, May 24). Six digital oilfield techs that hold promise for the oilsands. Retrieved 01 12, 2018, from JWN Energy: http://www.jwnenergy.com/article/2017/5/six-digital-oilfieldtechs-hold-promise-oilsands/

Wethe, D. (2017, July 26). Oilfield Rush to High-Tech Helps Smaller Companies Thrive. Retrieved 01 22, 2018, from Bloomberg: https://www.bloomberg.com/news/articles/2017-0726/oilfield-rush-to-high-tech-opens-doors-for-small-firms-to-thrive 